\title{
Determination of Trace Amounts of Palladium(II) in Water by Metal-Furnace Atomic Absorption Spectrometry after Preconcentration on Chitin
}

\author{
Hiroaki Minamisawa*, Yoshihito Tatehaba*, Nobumasa Arai* and Tadao OKUtani** \\ * Department of Liberal Arts and Basic Sciences, College of Industrial Technology, Nihon University, \\ Shinei-cho, Narashino, Chiba 275, Japan \\ ** Department of Industrial Chemistry, College of Science and Technology, Nihon University, \\ Kanda-Surugadai, Chiyoda, Tokyo 101, Japan
}

\begin{abstract}
Palladium(II) reacts with halogenide ions, such as chloride ion and bromide ion, to form anionic complexes. The acetylamino groups of chitin are protonated in an acidic medium, acting as an anion exchanger. The property of chitin was applied to the preconcentration and microdetermination of palladium(II). The palladium(II) chloro complex was quantitatively adsorbed onto chitin over the $\mathrm{pH}$ range of 2.5-4.0. The chitin which adsorbed the palladium(II) was separated from the sample solution by a membrane filter, and dispersed in pure water. The resulting suspension was introduced directly into a tungsten metal-furnace atomizer. An ashing temperature of $1000^{\circ} \mathrm{C}$ and an atomizing temperature of $2300^{\circ} \mathrm{C}$ were selected. The detection limit for palladium(II) was $0.06 \mu \mathrm{g} / 100 \mathrm{~cm}^{3}(S / N \geqq 3)$. The proposed method was applied to the determination of trace amounts of palladium(II) in water samples.
\end{abstract}

Keywords Palladium(II), protonated chitin, preconcentration, tungsten metal furnace atomic absorption spectrometry

Palladium is a noble metal which can be widely used as a catalyst for the oxidation of phenolic materials ${ }^{1-3}$ and electrical contact points. In the field of analytical science, palladium is used as a matrix modifier for the determination of several metals, such as molybdenum and thallium, by graphite-furnace atomic absorption spectrometry (AAS). ${ }^{4-6}$ In this way, palladium is widely used in various fields. Therefore, a quantitative understanding of palladium has become important. For that purpose, numerous AAS methods following preconcentration techniques, such as coprecipitation ${ }^{7}$, solvent extraction $^{8-10}$ and adsorption-elution ${ }^{11-17}$, have been developed. The adsorption-elution method is one of the effective preconcentration techniques. Activated carbon (AC) ${ }^{11}$, chelating resin ${ }^{12,13}$, ion-exchange resin ${ }^{14,15}$ and porous polymer ${ }^{16,17}$ were used as the adsorbent. This method can require a pertinent choice of the eluent and elution procedure. Thus, a direct injection method, in which the metal adsorbed-adsorbent/water suspension is introduced onto the furnace in electrothermal AAS, would be much more useful because of no need for an elution procedure.

One of the present authors has reported a method in which metal ions, such as beryllium ${ }^{18}$, indium ${ }^{19}$ and gold $^{20}$ adsorbed $\mathrm{AC} /$ water suspension, are injected directly into the graphite furnace or tungsten metal furnace. These methods are very simple and make it possible to determine ultratrace levels of the metal ions.
Chitin has recently been used for the preconcentration of anionic complexes of metal ions by using its property as an anion-exchanger in an acidic medium. This property of chitin was applied to the determination of some metal ions by AAS after preconcentrated onto chitin as their maleonitriledithiolate ${ }^{21}$ and 1-nitroso-3,6disulfo-2-naphtholate[nitoroso R(NR)] ${ }^{22,23}$ anionic complexes. Hoshi et al. have reported the spectrophotometric determination of iron(III) after being preconcentrated as its 8-hydroxyquinoline-5-sulfonate anionic complex. ${ }^{24}$ Hase et al. synthesized the dithiocarbamete-chitin, and used it for the preconcentration of some metal ions. ${ }^{25}$

The present authors reported a method for the determination of trace amounts of gold(III) by tungsten metal-furnace AAS with the direct injection of a chitin/ water suspension adsorbing gold(III) chloro anionic complex. ${ }^{26}$ This method is simple and useful because a chelating reagent, such as NR, and an elution procedure are unnecessary. Palladium(II) reacts with the chloride ion to form a stable anionic complex similar to gold(III). In this study, the method was extended to the determination of trace amounts of palladium(II) in water samples.

\section{Experimental}

\section{Apparatus}

A Seiko Instrument, Inc. SAS-7500 atomic absorption 
spectrophotometer equipped with a flameless atomizer (PS-200; a tungsten metal furnace) was used for all of the experimental work. A hollow-cathode lamp of palladium was operated at $10 \mathrm{~mA}$, and a deuterium lamp was used for background correction. All measurements were made in the peak-height mode.

An Iwaki glass TM-152 MIXER was used for dispersing the chitin/water suspension. The suspension was manually introduced into the tungsten metal furnace by an Eppendorf micropipet. A Horiba $\mathrm{M}-8 \mathrm{~L}$ pH meter was used for $\mathrm{pH}$ adjustments of the sample solution.

\section{Reagents}

A standard palladium(II) solution was prepared by the dilution of $1000 \mu \mathrm{g} / \mathrm{cm}^{3}$ atomic absorption standard (Wako Pure Chemicals Co., Ltd.) with $0.1 \mathrm{~mol} \mathrm{dm}^{-3}$ hydrochloric acid, as required. The standard solution was obtained by dissolving palladium(II) chloride in $1 \mathrm{~mol} \mathrm{dm}^{-3}$ hydrochloric acid. Palladium(II) has been used to form a palladium chloro anionic complex in standard solution, and its complex is very stable. A palladium(II) bromide solution was prepared by dissolving palladium(II) bromide (Nacalai Tesque Inc.) in hydrobromic acid, and was further diluted with water, as required. In this solution, palladium(II) has been used to form a palladium bromo anionic complex; its complex is very stable.

Chitin powder (Nacalai Tesque Inc.), prepared to a grain size of less than 300 mesh, was washed successively with $1 \mathrm{~mol} \mathrm{dm}^{-3}$ hydrochloric acid and water, then dried at $70^{\circ} \mathrm{C}$ for $24 \mathrm{~h}$ in a dry oven. Highly purified water was obtained using an Organo Puric-S system. All other reagents were of analytical and extra-pure reagent grade.

\section{Adsorption experiments}

The experiments were carried out by a batch method. To a $100 \mathrm{~cm}^{3}$ of sample solution containing palladium(II), $100 \mathrm{mg}$ of chitin was added after adjusting its $\mathrm{pH}$ to the optimum range with diluted ammonia water and nitric acid. The solution was stirred for $30 \mathrm{~min}$ with a magnetic stirrer, and separated with a membrane filter. The adsorption amounts of palladium(II) onto chitin were determined in order to measure the concentration of the resulting filtrate.

\section{Analytical procedure}

The $\mathrm{pH}$ of sample solution $\left(100-500 \mathrm{~cm}^{3}\right)$, containing less than $2.0 \mu \mathrm{g}$ of palladium(II), was adjusted to 3.0 with hydrochloric acid and diluted ammonia water. A $50 \mathrm{mg}$ of chitin was added to the solution. The mixture was stirred for $15 \mathrm{~min}$ with a magnetic stirrer so as to adsorb palladium(II) onto the chitin. The palladium(II) which was quantitatively adsorbed onto the chitin was separated from the sample solution through a membrane filter (pore size, $8.0 \mu \mathrm{m}$; Millipore Co., Ltd.). The palladium(II) adsorbed onto the chitin was then carefully transferred into a stoppered test tube with $5.0 \mathrm{~cm}^{3}$ of water, and dispersed using an ultrasonic agitator. After
Table 1 Instrumental operating conditions

\begin{tabular}{lc} 
Wavelength $/ \mathrm{nm}$ & 244.79 \\
Slit width $/ \mathrm{nm}$ & 0.20 \\
Lamp current $/ \mathrm{mA}$ & 10 \\
Flow rate of purge gas $/ \mathrm{dm}^{3} \mathrm{~min}^{-1}$ & $\mathrm{Ar:} 3.0$ \\
& $\mathrm{H}_{2}: 1.0$ \\
Injection volume $/ \mathrm{mm}^{3}$ & 10 \\
Drying & $130^{\circ} \mathrm{C} / 30 \mathrm{~s}$ \\
Ashing & $1000^{\circ} \mathrm{C} / 10 \mathrm{~s}$ \\
Atomizing & $2300^{\circ} \mathrm{C} / 4 \mathrm{~s}$ \\
\hline
\end{tabular}

shaking for $15 \mathrm{~s}$, a $10 \mathrm{~mm}^{3}$ aliquot of the palladium(II)adsorbed chitin/water suspension was injected directly into the tungsten metal furnace with a micro pipette (Eppendorf Co., Ltd.) within $10 \mathrm{~s}$. The absorbance (peak height) was measured under the instrumental conditions listed in Table 1.

\section{Results and Discussion}

\section{Adsorption of palladium(II)}

Palladium(II) reacts with halogenide ions, such as chloride ion and bromide ion, to form anionic complexes. Thus, the effect of the $\mathrm{pH}$ on the adsorption of palladium(II) chloro complex and palladium(II) bromo complex onto chitin from an aqueous solution were investigated. The results are shown in Fig. 1. The palladium(II) chloro complex and palladium(II) bromo complex were quantitatively adsorbed onto chitin in the $\mathrm{pH}$ range from 2.5 to 4.0 , respectively. The adsorption rate decreased along with a decrease in the $\mathrm{pH}$ at a lower $\mathrm{pH}$ range. These results were the same as that described for gold(III) halogenide anionic complexes. ${ }^{26}$ The adsorption rate also decreased along with an increase in the $\mathrm{pH}$ at a higher $\mathrm{pH}$ range because of incomplete adsorption of their anionic complexes, since chitin dose not act as an anion exchanger in the neutral to basic $\mathrm{pH}$ region. Further, the adsorption isotherms of the palladium(II) chloro complex and palladium(II) bromo complex onto chitin from an aqueous solution at the optimum $\mathrm{pH}$ range were investigated.

The Freundlich equation is generally applicable for the monolayer adsorption of a single species from the liquid to the solid phase. ${ }^{27}$ The equation can be expressed as

$$
q=k C^{1 / n}
$$

and

$$
\log q=\log k+1 / n \log C,
$$

where $q$ is the adsorption amount $\left(\mathrm{mg} \mathrm{g}^{-1}\right), C$ is the residual amount $\left(\mathrm{mg} \mathrm{g}^{-1}\right)$ and $k$ and $1 / n$ are arbitrary parameters.

These isotherms obeyed the Freundlich equation; the results are shown in Fig. 2. In Fig. 2, the plots of $\log C$ 


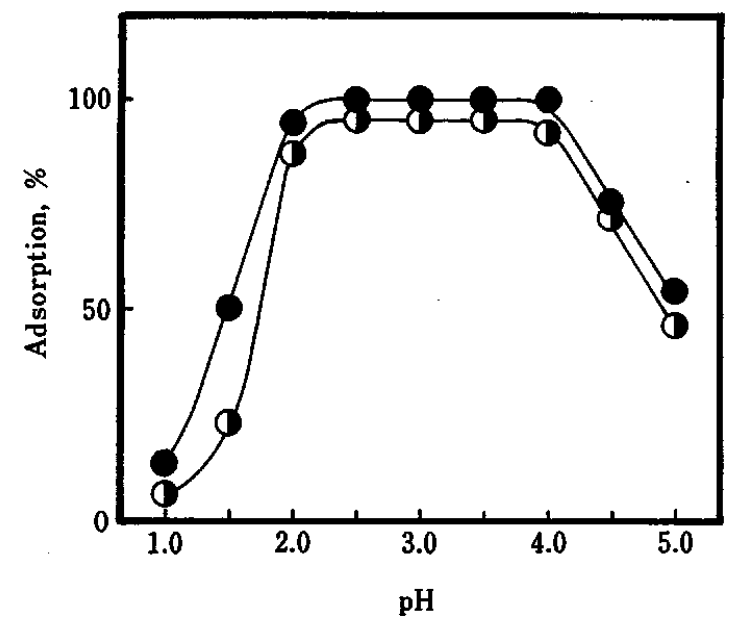

Fig. 1 Effect of $\mathrm{pH}$ on the adsorption of palladium(II). (O), palladium(II) chloro complex; (O), palladium(II) bromo complex; palladium(II) $10 \mu \mathrm{g} / 100 \mathrm{~cm}^{3}$; chitin, $100 \mathrm{mg}$; adsorption time, $30 \mathrm{~min}$.

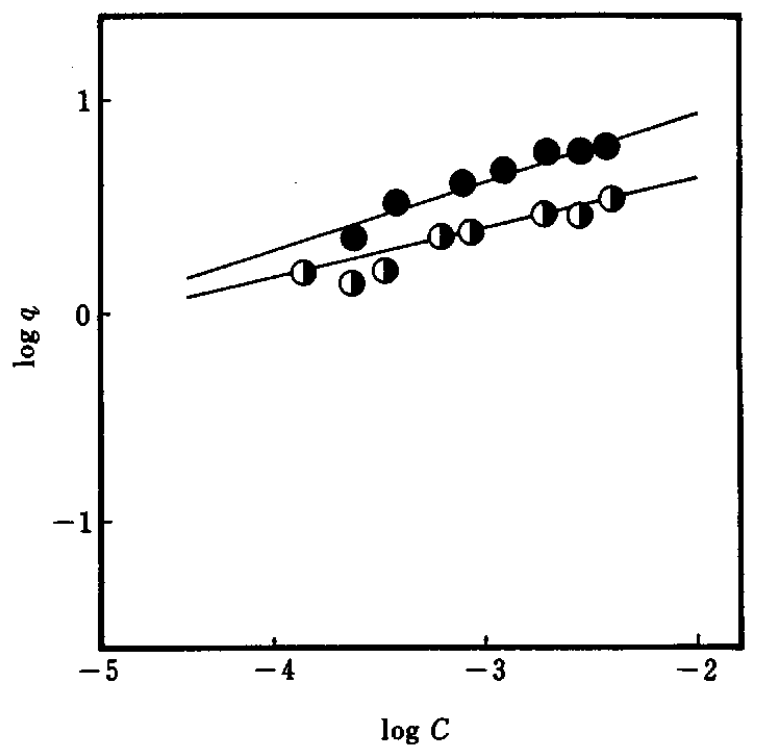

Fig. 2 Freundlich plots of palladium(II) adsorption on chitin. (O), palladium(II) chloro complex; (O), palladium(II) bromo complex; chitin, $100 \mathrm{mg}$; pH, 3.0; volume of sample solution, $100 \mathrm{~cm}^{3}$; temperature, room temp.

vs. $\log q$ describe a straight line, respectively. The Freundlich equation parameters obtained from Fig. 2 are summarized in Table 2. In general, the value of $1 / n$ is usually less than 1 for a substance which is readily adsorbed, while the value is greater than 2 for a substance which is not readily adsorbed. The values for the palladium(II) chloro complex and the palladium(II) bromo complex were less than 1 , respectively. Consequently, both the palladium(II) chloro complex and palladium(II) bromo complex can be classified as a
Table 2 Freundlich's equation parameter

\begin{tabular}{ccc}
\hline Metal species & $k / \mathrm{mg} \mathrm{g}^{-1}$ & $1 / n$ \\
\hline Palladium(II) chloro complex & 44.1 & 0.34 \\
Palladium(II) bromo complex & 15.8 & 0.26 \\
\hline
\end{tabular}

substance which is readily adsorbed onto chitin. Moreover, the adsorption ability is also higher when the value of $k$ is larger. As shown in Table 2, the $k$ value for palladium(II) chloro complex is 3-times larger than that for the palladium(II) bromo complex. Therefore, the use of the palladium(II) chloro complex is more effective for the preconcentration of trace amounts of palladium(II).

In the following part, palladium(II) means palladium(II) chloro complex.

\section{Analytical conditions}

The effects of the ashing and atomizing temperatures on the absorbances of palladium for the palladium(II)adsorbed chitin/water suspension were investigated by varying the temperature from 400 to $1600^{\circ}$ Cand 2000 to $2800^{\circ} \mathrm{C}$, respectively. The other conditions were kept constant, as shown in Table 1 . The relationship between the absorbance and the ashing temperature is shown in Fig. 3. In the case of the suspension, the maximum absorbance of palladium was obtained in the range from 400 to $1200^{\circ} \mathrm{C}$. When the temperature at the ashing stage was below $400^{\circ} \mathrm{C}$, background absorption appeared due to smoke evolution from the chitin, although it did not interfere with the absorbance measurement. When the temperature at the ashing stage was above $1200^{\circ} \mathrm{C}$, the absorbances for both the palladium(II) standard solution and the suspension obtained with the proposed method decreased, due to a

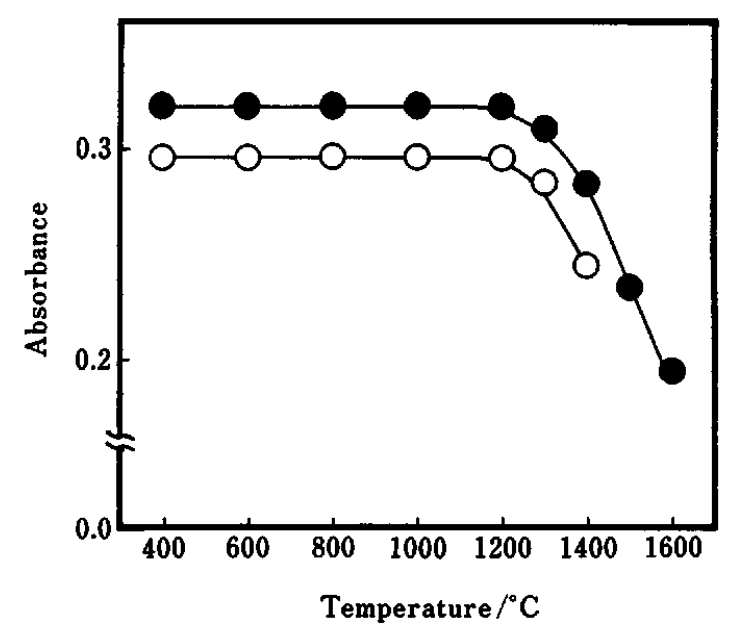

Fig. 3 Effect of ashing temperature on the absorbance of palladium. (O), palladium(II) adsorbed chitin/water suspension; (O), palladium(II) aqueous standard solution; injection volume, $10 \mathrm{~mm}^{3}$. 
possible loss of palladium by partial volatilization during the ashing stage.

The effect of the atomizing temperature on the sensitivity was similarly studied. In the case of the suspension, the maximum absorbance of palladium was obtained in the range from 2000 to $2500^{\circ} \mathrm{C}$.

It was observed that the chitin acts as a sensitizer for palladium during the atomization step; that is, the absorbance of the suspension increases in comparison with that of the palladium(II) standard solution.

Considering these results, we selected an ashing temperature of $1000^{\circ} \mathrm{C}$ and an atomizing temperature of $2300^{\circ} \mathrm{C}$ for palladium analyses by metal-furnace AAS.

\section{Effect of the $\mathrm{pH}$ and the amounts of chitin}

The effects of the $\mathrm{pH}$ on the adsorption of palladium(II) onto chitin was examined using the proposed analytical procedure. Palladium(II) was quantitatively adsorbed onto chitin in the $\mathrm{pH}$ range from 2.5 to 4.0 , as mentioned before. Moreover, the effect of the amounts of chitin on the adsorption of palladium(II) was investigated. The quantitative adsorption of palladium(II) was obtained at more than $40 \mathrm{mg}$ of chitin. However, more than $100 \mathrm{mg}$ of the chitin was employed for the analytical procedure, the chitin was not well dispersed into water, and it was difficult to exactly take a definite amount of the chitin suspension. Accordingly, $50 \mathrm{mg}$ of chitin was used for the determination of palladium(II) in this work.

\section{Effects of the adsorption time and dispersion time}

Palladium(II) was quantitatively adsorbed onto chitin by stirring for more than $10 \mathrm{~min}$ with a magnetic stirrer. Therefore, an adsorption time of $15 \mathrm{~min}$ is employed for the analytical procedure.

Palladium(II)-adsorbed chitin was dispersed homogeneously in $5.0 \mathrm{~cm}^{3}$ of water using an ultrasonic agitator. Then, a $10 \mathrm{~mm}^{3}$ aliquot of the suspension was injected directly into the tungsten metal furnace. Although the absorbance signal decreased rapidly in the case of standing for over $20 \mathrm{~s}$ after dispersion, a constant absorbance was obtained within $10 \mathrm{~s}$.

\section{Calibration graph and detection limit}

After the analytical procedure was applied to a $100 \mathrm{~cm}^{3}$ sample solution containing $1.0 \mu \mathrm{g}$ of palladium(II), the same procedure was applied again to the filtrate. No palladium(II) was found in the filtrate, which means that the recoveries of palladium(II) was about $100 \%$. The calibration curves obtained with the proposed analytical procedure for a $100 \mathrm{~cm}^{3}$ of sample solution was linear up to $2.0 \mu \mathrm{g}$ palladium(II). The influence of the sample size was investigated by varying the volume of a sample solution containing $1.0 \mu \mathrm{g}$ of palladium(II). A nearly quantitative recovery was obtained with the proposed analytical procedure in the $100-500 \mathrm{~cm}^{3}$ range. Thus, use for a $500 \mathrm{~cm}^{3}$ sample solution can give a concentration factor of 100 . The detection limit $(S / N \geqq 3)$ for palladium(II) was $0.06 \mu \mathrm{g} / 500 \mathrm{~cm}^{3}$. The relative
Table 3 Effects of diverse ions on the recovery of palladium(II)

\begin{tabular}{lcc}
\hline Diverse ion & Amounts added $/ \mathrm{mg}$ & Recovery, $\%$ \\
\hline $\mathrm{Co}(\mathrm{II})$ & 0.05 & 98 \\
$\mathrm{Ni}(\mathrm{II})$ & 0.05 & 97 \\
$\mathrm{Cu}(\mathrm{II})$ & 0.1 & 98 \\
$\mathrm{Zn}(\mathrm{II})$ & 0.1 & 100 \\
$\mathrm{~Pb}(\mathrm{II})$ & 0.1 & 92 \\
$\mathrm{Fe}(\mathrm{III})$ & 1.0 & 98 \\
$\mathrm{Al}(\mathrm{III})$ & 0.1 & 100 \\
$\mathrm{Mg}(\mathrm{II})$ & 0.1 & 100 \\
$\mathrm{~K}(\mathrm{I})$ & 1.0 & 100 \\
$\mathrm{Na}(\mathrm{I})$ & 1.0 & 98 \\
$\mathrm{Ca}(\mathrm{II})$ & 1.0 & 97 \\
$\mathrm{Cl}{ }^{-}$ & 10 & 100 \\
$\mathrm{CH}_{3} \mathrm{COO}^{-}$ & 10 & 100 \\
$\mathrm{PO}_{4}{ }^{2-}$ & 10 & 98 \\
$\mathrm{NO}_{3}{ }^{-}$ & 10 & 100 \\
$\mathrm{SO}_{4}{ }^{2-}$ & 10 & 97 \\
\hline
\end{tabular}

Palladium(II), $1.0 \mu \mathrm{g} / 100 \mathrm{~cm}^{3}$; chitin, $50 \mathrm{mg} ; \mathrm{pH}, 3.0$; adsorption time, $15 \mathrm{~min}$.

standard deviations of ten measurements was $4.0-5.0 \%$ at $0.1 \mu \mathrm{g} / 500 \mathrm{~cm}^{3}$.

\section{Effect of diverse ions}

The effects of diverse ions on the determination of palladium(II) were investigated. The recoveries of palladium(II) by the proposed analytical procedure were measured in $100 \mathrm{~cm}^{3}$ solutions containing $1.0 \mu \mathrm{g}$ of palladium(II) and matrix ions. The experimental results are shown in Table 3. These results show that a number of common cations, such as calcium(II), potassium(I), sodium(I) and iron(III), did not interfere with the determination of palladium(II). Similarly, various anions, such as $\mathrm{Cl}^{-}, \mathrm{CH}_{3} \mathrm{COO}^{-}, \mathrm{NO}_{3}{ }^{-}$and $\mathrm{SO}_{4}{ }^{2-}$, did not interfere. Therefore, the proposed analytical procedure can be applied to the determination of palladium(II) in water samples.

\section{Determination of palladium(II) in water samples}

The palladium(II) contents in river water and plating wastewater were measured by the proposed analytical procedure after suspended matter was removed using a membrane filter (pore size, $0.45 \mu \mathrm{m}$; Millipore Co., Ltd.). Table 4 shows the results of analyses of the original sample solution and of sample solutions to which known amounts of palladium(II) were spiked. The recoveries of the spiked palladium(II) were over $99 \%$.

In conclusion, the proposed method, in which the palladium(II) chloro anionic complex is quantitatively adsorbed onto chitin powder, is effective for the preconcentration of trace amounts of palladium(II). The proposed method is rapid and simple, and applicable to the determination of trace amounts of palladium(II) in water samples. 
Table 4 Determination of palladium(II) in water samples

\begin{tabular}{cccc}
\hline & \multicolumn{3}{c}{ Palladium(II) } \\
\cline { 2 - 4 } Sample & Added/ & Found/ & Recovery, \\
& $\mu \mathrm{g}$ & $\mu \mathrm{g}$ & $\%$ \\
\hline River water $^{\mathrm{a}}$ & - & N.D. & - \\
(Kimitsu, Chiba-pref.) & 0.10 & 0.100 & 100 \\
Plating factory wastewater $^{\mathrm{b}}$ & 0.20 & 0.202 & 102 \\
& 0.10 & 0.171 & - \\
& 0.20 & 0.372 & 100 \\
\hline
\end{tabular}

N.D. $\leqq 0.06 \mu \mathrm{g}$ palladium(II) $/ 100-500 \mathrm{~cm}^{3}$; chitin, $50 \mathrm{mg}$; adsorption time, $15 \mathrm{~min}$.

a. Sample volume, $500 \mathrm{~cm}^{3}$.

b. Sample volume, $100 \mathrm{~cm}^{3}$.

\section{References}

1. H. Grennberg, A. Gogoll and J. E. Backvall, J. Org. Chem., 56, 5808 (1991).

2. T. Jintoku, T. Takagi, Y. Fujiwara, Y. Fuchita and K. Hiraki, Bull. Chem. Soc. Jpn., 63, 438 (1990).

3. T. Hirao, T. Murakami, M. Ohno and Y. Ohshiro, Chem. Lett., 1991, 299.

4. X. Shan, Z. Ni and L. Zhang, Talanta, 31, 150 (1984).

5. P. Bermejo-Barrera, J. Moreda-Pineiro, A. MoredaPineiro and A. Bermejo-Barrera, Anal. Chim. Acta, 296, 181 (1994).

6. M. Yizai, L. Zhikun, W. Xiaohui and W. Jiuzhen, J. Anal. At. Spectrom., 9, 679 (1994).

7. H. Niskavaara and E. Kontas, Anal. Chim. Acta, 231, 273 (1990).
8. M. Aihara and M. Kiboku, Bunseki Kagaku, 29, 833 (1980).

9. S. Terashima, Bunseki Kagaku, 39, 585 (1990).

10. A. Tong and Y. Akama, Chemistry Express, 5, 705 (1990).

11. E. Jackwerth, J. Lohmar and G. Wittler, Fresenius' $Z$. Anal. Chem., 226, 1 (1973).

12. H. Matsunaga and T. Suzuki, Nippon Kagaku Kaishi, 1986, 859.

13. J. Chwqastowaka and E. Kosiarska, Talanta, 35, 439 (1988).

14. T. Braun and A. B. Farag, Anal. Chim. Acta, 69, 85 (1974).

15. A. Chow and D. Buksak, Can. J. Chem., 53, 1373 (1975).

16. X. G. Xang and E. Jackwerth, Fresenius' Z. Anal. Chem., 331, 588 (1988).

17. L. Elci, Anal. Lett., 26, 1025 (1993).

18. T. Okutani, Y. Tsuruta and A. Sakuragawa, Anal. Chem., 65, 1273 (1993).

19. J. Wei, Q. Liu and T. Okutani, Anal. Sci., 11, 465 (1994).

20. A. Uzawa, W. Yoshimura and T. Okutani, Bunseki Kagaku, 44, 391 (1995).

21. K. Komori, S. Igarashi and T. Yotsuyanagi, Bunseki Kagaku, 35, 890 (1986).

22. H. Minamisawa, T. Hokazono, N. Arai and T. Okutani, Nippn Kagaku Kaishi, 1993, 937.

23. H. Minamisawa, N. Arai and T. Okutani, Anal. Sci., 11, 961 (1995).

24. S. Hoshi, T. Tomizuka, C. Enjo, Y. Haga, M. Uto and K. Akatsuka, Anal. Sci., 11, 729 (1995).

25. A. Hase, T. Kawabata and T. Terada, Anal. Sci., 6, 747 (1990).

26. H. Minamisawa, N. Arai, Y. Tatehaba and T. Okutani, Nippon Kagaku Kaishi, 1995, 512.

27. K. Kawazoe, "Kyuuchaku (Adsorption, in Japanese)", p. 20, Nikkankougyoushinbunsha, Tokyo, 1957.

(Received June 7, 1996) (Accepted September 4, 1996) 